Accepted manuscript of Environ. Sci. Pollut. R. 21 (2014) 11126-11134 http://doi: 10.1007/s11356-014-2527-2

\title{
Degradation of industrial surfactants by photocatalysis combined with ozonation
}

\author{
Zoltán Zsilák ${ }^{1}$, Orsolya Fónagy ${ }^{1}$, Erzsébet Szabó-Bárdos ${ }^{1}$, Ottó Horváth ${ }^{1 *}$, \\ Krisztián Horváth ${ }^{2}$, Péter Hajós ${ }^{2}$ \\ University of Pannonia, Institute of Chemistry \\ ${ }^{1}$ Department of General and Inorganic Chemistry \\ ${ }^{2}$ Department of Analytical Chemistry \\ H-8201 Veszprém, P.O.Box 158, Hungary \\ *Corresponding author e-mail: otto@mk.uni-pannon.hu; phone: +36 88624 159; \\ fax: +36 88624548
}

\begin{abstract}
The efficiency of titanium dioxide-mediated photocatalytic degradation of pollutants can be enhanced by combination with another advanced oxidation procedure such as ozonation. Mineralization of hydroxy- and dihydroxybenzenesulfonate based on these methods, both individually and combined, was investigated by monitoring the total organic carbon (TOC) content, sulfate concentration, $\mathrm{pH}, \mathrm{HPLC}$ as well as the absorption spectral changes. The mineralization efficiency of the combined procedure significantly exceeded the sum of those of the individual techniques. The comparison of the disappearance of the starting material and the formation of the sulfate ions indicates that desulfonation is not the primary step of the degradation. Moreover, in the case of the combined method, ring- cleavage, and thus, partial mineralization can occur without desulfonation. Efficient degradation of other, widely used industrial surfactants, such as alkylbenzene sulfonates and alkyl ether sulfates, was also achieved by heterogeneous photocatalysis combined with ozonation, offering an applicable method for the removal of these pollutants.
\end{abstract}

Keywords: hydroxy- and dihydroxybenzenesulfonate; alkylbenzene sulfonates; alkyl ether sulfates; $\mathrm{TiO}_{2}$ based photocatalysis; oxidative degradation; ozonation; synergy. 


\section{Introduction}

Sulfonated surface active compounds are widespread in consumer products and in many industrial processes (Tully 1997). Linear alkylbenzene sulfonates (LASs) are applied as surfactants in laundry and cleansing products. Alkyl ether sulfates are used in many cosmetic products for their foaming and emulsifying properties. Benzene- and naphthalenesulfonates are utilized mainly as intermediates for the manufacturing of azo dyestuffs, pharmaceuticals and tanning agents.

While LASs compounds were found to be biodegradable enough (Takada and Ishiwatari 1990; Hashim et al. 1992), aromatic sulfonates without long alkyl side chains proved to be biorecalcitrant (Cain 1981). Benzene- and naphthalenesulfonates with sulfo, nitro and amino groups are characterized by especially low biodegradability (Brilon et al. 1981; Zürrer et al. 1987; Wittich et al. 1988). Due to their strong hydrophilic character (low n-octanol-water partition coefficients (Greim et al. 1994)) and high mobility within aquatic systems, polar aromatic sulfonates are easily transported from sewers to surface waters (Isobe et al. 2004). These properties make them potentially hazardous with respect to contamination of ground water and drinking water supplies (Reemtsma 1996).

Various methods have been tested for the degradation of these sulfonated surfactants as pollutans over the past two decades. Mineralization of benzenesulfonates was realized by contact glow discharge electrolysis (Amano et al. 2004, 2006). Ozonation was found to be efficient only in the presence of activated carbon, due to the high local concentration of the adsorbed reactants (Faria et al. 2008). Oxidative degradation of 1,5-naphthalenedisulfonic acid was achieved in electrochemical way in situ generating silver(II) or peroxydisulfate as mediators (Ravera et al. 2004) as well as in the presence of hydrogen peroxide activated by microwaves or UV irradiation (Ravera et al. 2009, 2010). Sonication was also applied for degradation of alkylbenzene sulfonates (Abu-Hassan et al. 2006). 
Photocatalytic procedures proved to be suitable for the treatment of water polluted with inorganic and especially organic contaminants, e.g., sulfonated surfactants such as lauryl sulfate (Horváth and Huszánk 2003, Horváth et al. 2005), alkylbenzene sulfonates (Zhang et al. 2003; Fernández et al. 2004), and naphthalenesulfonates (Arslan-Alaton et al. 2010; Avetta et al. 2012). In heterogeneous photocatalytic methods utilized for the degradation of organic pollutants the most widely used material is titanium dioxide, $\mathrm{TiO}_{2}$ (Szabó-Bárdos et al. 2003, 2004, Fabbri et al. 2006, Patsoura et al. 2007). Efficient photocatalytic mineralization of 1,5-naphthalenedisulfonate (Szabó-Bárdos et al. 2008b) and benzenesulfonate (Sangchakr et al. 1995; Szabó-Bárdos et al. 2011) was also realized in titanium dioxide suspension. In $\mathrm{TiO}_{2}$-mediated photocatalysis the most efficient oxidizing species is hydroxyl radical, which is generated in aqueous systems via the oxidation of adsorbed water by the positively charged hole $\left(\mathrm{h}_{\mathrm{vb}}{ }^{+}\right)$formed in the valence band of the semiconductor upon excitation (Hoffmann et al. 1995).

$$
\begin{aligned}
& \mathrm{TiO}_{2}+\mathrm{h} v \rightarrow \mathrm{TiO}_{2}\left(\mathrm{e}_{\mathrm{cb}}{ }^{-}+\mathrm{h}_{\mathrm{vb}}{ }^{+}\right) \\
& \mathrm{TiO}_{2}\left(\mathrm{~h}_{\mathrm{vb}}{ }^{+}\right)+\mathrm{H}_{2} \mathrm{O}_{\mathrm{ads}} \rightarrow \mathrm{TiO}_{2}+\mathrm{HO}^{\bullet}+\mathrm{H}^{+}
\end{aligned}
$$

The holes may also be trapped by 2 -fold coordinated terminal oxygen ions of the $\mathrm{TiO}_{2}$ lattice, $>\mathrm{O}_{\mathrm{s}}{ }^{2-}$ (protonated or deprotonated, depending on $\mathrm{pH}$ )

$$
\begin{aligned}
& >\mathrm{O}^{2-}+\mathrm{h}_{\mathrm{vb}}{ }^{+} \rightarrow>\mathrm{O}^{--} \\
& >\mathrm{O}_{\mathrm{s}}{ }^{2-}+\mathrm{H}_{\mathrm{aq}}{ }^{+}+\mathrm{h}_{\mathrm{vb}}{ }^{+} \rightarrow>\left(\mathrm{HO}_{\mathrm{s}}{ }^{-}\right)
\end{aligned}
$$

The radicals formed in these reactions can oxidize adsorbed organic solutes via an indirect electron transfer mechanism, resulting in dissolved organic radicals (Salvador 2007).

In air-saturated systems, electrons $\left(\mathrm{e}_{\mathrm{cb}}{ }^{-}\right)$photogenerated in the conduction band can reduce dissolved oxygen, resulting in the formation of superoxide and peroxide ions.

$$
\mathrm{TiO}_{2}\left(\mathrm{e}_{\mathrm{cb}}{ }^{-}\right)+\mathrm{O}_{2 \mathrm{ads}} \rightarrow \mathrm{TiO}_{2}+\mathrm{O}_{2}{ }^{\bullet-}
$$


$\mathrm{TiO}_{2}\left(\mathrm{e}_{\mathrm{cb}}{ }^{-}\right)+\mathrm{O}_{2}^{\bullet-} \rightarrow \mathrm{TiO}_{2}+\mathrm{O}_{2}^{2-}$

Although $\mathrm{TiO}_{2}$ based photocatalysis proved to be an efficient technique for degradation of sulfonated surfactants, its combination with another type of advanced oxidation procedure can enhance the efficiency of their mineralization. Even if ozonation is an appropriate candidate for this purpose, just recently started to apply this combined procedure for the degradation of these pollutants (Oyama et al. 2009). It has currently been observed in our laboratory that combination of heterogeneous photocatalysis with ozonation results in a synergistic effect in the increase of the mineralization rate of benzenesulfonate (Zsilák et al. 2013). This promising result inspired us to continue the investigation of the combined technique, applying it for the degradation of other surfactants. Our choice involved hydroxyand dihydroxybenzenesulfonates because they are key intermediates in the oxidative degradation of the previously studied benzenesulfonate. The main goal of their study was to investigate if synergistic effect occurs in these cases too, and to get some information regarding the mechanism of their mineralization. Besides, the degradation of two other types of detergents, linear alkyl benzenesulfonates and alkyl ether sulfates was also studied by heterogeneous photocatalysis in aerated and ozonated systems. The representatives of these two groups are widespread industrial surfactants. Thus, the results of this work may also be utilized in the design of new catalytic procedures for wastewater treatment.

\section{Experimental}

\subsection{Materials}

In all experiments of this work, the titanium dioxide catalyst used was Degussa P25 (70\% anatase, $30 \%$ rutile; with a surface area of $50 \mathrm{~m}^{2} \mathrm{~g}^{-1}$ ). The concentration of $\mathrm{TiO}_{2}$ was $1 \mathrm{~g} \mathrm{dm}^{-3}$ in all cases. Reagent grade 4-hydroxybenzenesulfonic acid (HBS) and 2,5dihydroxybenzenesulfonic acid (DHBS) were purchased from Merck. Other materials, such as 
methylene blue or chloroform were also reagent grade. $\mathrm{H}_{2} \mathrm{O}_{2}$ as an oxidizer was introduced into the reaction mixtures from $35 \%$ stock solution. The samples of linear alkylbenzene sulfonates (LAS, $\mathrm{C}_{10}-\mathrm{C}_{13}$ ) and alkyl ether sulfates (LES, $\left.\mathrm{C}_{12}-\mathrm{C}_{14}\right)$ were received from a detergent manufacturer. Compressed air was bubbled through the reaction mixtures from gas bottles, serving for both stirring and (with its $\mathrm{O}_{2}$ content) as electron acceptor. Beside dissolved oxygen $\left(\mathrm{O}_{2}\right)$, in most of the experiments, $\mathrm{O}_{3}$ (produced by a LAB2B ozone generator) was also introduced in the same air stream. In all of these experiments, ozone dosage was adjusted to $0.35 \mathrm{mM} \mathrm{min}{ }^{-1}$. High purity water used as solvent in this study was double distilled and then purified with a Milli-Q system. In order not to disturb the subsequent analyses, no buffer was used in the reaction mixtures to be irradiated.

\subsection{Photochemical experiments}

Photochemical experiments were carried out by using a laboratory-scale reactor with an effective (irradiated) volume of $2.5 \mathrm{dm}^{3}$. The heterogeneous reaction mixture $\left(\mathrm{TiO}_{2}\right.$ suspension) of $3 \mathrm{dm}^{3}$ was circulated by application of a peristaltic pump through the reactor and the buffer vessel and by continuously bubbling air a flow rate of $40 \mathrm{dm}^{3} \mathrm{~h}^{-1}$ within the reactor. The photon flux of the internal light source $\left(40 \mathrm{~W}, \lambda_{\max }=350 \mathrm{~nm}\right.$, i.e., UVA range) was determined by tris(oxalato)ferrate(III) chemical actinometry (Rabek, 1982, Kirk et al, 1983). It was estimated to be $4.3 \times 10^{-6}$ mol photon $\mathrm{dm}^{-3} \mathrm{~s}^{-1}$.

\subsection{Analytical procedures}

For analysis, $4 \mathrm{~cm}^{3}$ samples were taken with a syringe from the reactor through a septum. The solid phase of samples, when necessary, was removed by filtration using Millipore MillexLCR PTFE $0.45 \mu \mathrm{m}$ filters. The $\mathrm{pH}$ of the aqueous phase of the reaction mixture was measured with SEN Tix 41 electrode. 
The concentrations of 4-hydroxybenzenesulfonate and 2,5-dihydroxybenzenesulfonate were monitored by application of an Agilent 1290 Infinity HPLC system (Agilent Technologies, Waldbroen, Germany) using UV detection (210, 230 and $254.4 \mathrm{~nm})$ and Zorbax Eclipse Plus C18 column $(50 \times 2.1 \mathrm{~mm}, 1.8 \mu \mathrm{m})$ at $40{ }^{\circ} \mathrm{C}$. The injection volume was $2 \mu \mathrm{L}$. The mobile phase was a water-methanol mixture (98:2) containing $0.1 \%(\mathrm{v} / \mathrm{v})$ phosphoric acid. The flow rate of eluent was $0.5 \mathrm{ml} / \mathrm{min}$.

The concentrations of alkylbenzene sulfonates and alkyl ether sulfates were photometrically determined (Horváth and Huszánk 2003). $0.2 \mathrm{~cm}^{3}$ of the sample was diluted by distilled water up to $100 \mathrm{~cm}^{3} .25 \mathrm{~cm}^{3}$ were added to the diluted sample from the following solution. $30 \mathrm{~cm}^{3}$ of a $1 \mathrm{~g} \mathrm{dm}^{-3}$ methylene blue aqueous solution, $6.8 \mathrm{~cm}^{3} \mathrm{cc} \mathrm{H}_{2} \mathrm{SO}_{4}$ and $50 \mathrm{~g}$ $\mathrm{Na}_{2} \mathrm{HPO}_{4} \mathrm{H}_{2} \mathrm{O}$ were mixed and diluted by distilled water to $1 \mathrm{dm}^{3} .10 \mathrm{~cm}^{3}$ chloroform was also added to this mixture. Methylene blue and these surfactants form adducts, which dissolve in chloroform (organic phase). After the extraction, the absorbance of the organic phase was measured at $652 \mathrm{~nm}$ in a $0.5-\mathrm{cm}$ quartz cell. For both types of concentration measurements previously recorded calibration curves were used. Ozone concentration was determined by iodometry, using sodium iodide as reagent and sodium thiosulfate for the titration of the iodine formed (Tjahjanto et al. 2012).

The absorption spectra were recorded with a Specord S 100 diode array spectrophotometer, using quartz cuvettes of various pathlengths. Mineralization was followed by measuring the total organic carbon (TOC) concentration, by application of a Thermo Electron Corporation TOC TN 1200 apparatus.

Sulfate concentration was followed by a Dionex DX300 ion chromatographic system (Dionex, Sunnyvale, CA, USA) using suppressed conductivity detection. The injection volume was $50 \mu \mathrm{L}$. Separations were carried out by a Dionex IonPac AS4A-SC $(250 \times 4 \mathrm{~mm})$ 
analytical column. The concentration, $\mathrm{pH}$ and flow rate of the carbonate eluent were $3.5 \mathrm{mM}$, 10.2 and $1.2 \mathrm{ml} \mathrm{min}^{-1}$.

The rate (and the correponding concentration) values at a given parameter set of conditions are averages determined from 3 experimental runs. The error of the values obtained is less than $3 \%$.

\section{Results and Discussion}

\subsection{Mineralization of 4-hydroxybenzenesulfonate (HBS) under various conditions}

The mineralization of HBS was examined by using $\mathrm{TiO}_{2}$-mediated photocatalysis (air/ $\left./ \mathrm{TiO}_{2} / \mathrm{UV}\right)$, ozonation $\left(\mathrm{O}_{3} / \mathrm{UV}\right)$, and their combination $\left(\mathrm{O}_{3} / \mathrm{TiO}_{2} / \mathrm{UV}\right)$. Fig. 1A displays the change of TOC in systems containing HBS of $10^{-3} \mathrm{M}$ initial concentration, during 180-min treatment by these methods.

Insert Fig. 1 about here

The mineralization efficiency of ozonation proved to be rather modest (with the initial rate of $0.0236 \mathrm{mg} \mathrm{dm}^{-3} \mathrm{~min}^{-1}$ regarding the TOC change). The mineralization rate with irradiated $\mathrm{TiO}_{2}$ in the presence of dissolved oxygen (air/TiO $/ \mathrm{UV}$ ) was considerably (about 4 times) higher $\left(0.096 \mathrm{mg} \mathrm{dm}^{-3} \mathrm{~min}^{-1}\right.$ initial rate) than in the previous case, demonstrating the much more significant oxidation power of titanium dioxide based photocatalysis. Combination of this method with ozonation $\left(\mathrm{O}_{3} / \mathrm{TiO}_{2} / \mathrm{UV}\right)$ increased the mineralization efficiency (to $0.228 \mathrm{mg} \mathrm{dm}^{-3} \mathrm{~min}^{-1}$ initial rate) so that it exceeded the sum of those observed with the two individual methods. A similar synergistic effect was experienced in our quite recent study on the mineralization of benzenesulfonate (Zsilák et al. 2013) and in an earlier work regarding the degradation of dibutyl phthalate (Li et al, 2005). This phenomenon can be attributed to the following reactions (Agustina et al, 2005):

- Direct electron transfer from $\mathrm{TiO}_{2}$ to $\mathrm{O}_{3}$ : 


$$
\begin{aligned}
& \mathrm{e}_{\mathrm{cb}}{ }^{-}+\mathrm{O}_{3} \rightarrow \mathrm{O}_{3}{ }^{--} \\
& \mathrm{O}_{2}{ }^{--}+\mathrm{O}_{3} \rightarrow \mathrm{O}_{3}{ }^{-}+\mathrm{O}_{2} \\
& \mathrm{O}_{3}{ }^{-}+\mathrm{H}^{+} \rightarrow \mathrm{HO}_{3}{ }^{-} \\
& \mathrm{HO}_{3}{ }^{\cdot} \rightarrow \mathrm{O}_{2}+{ }^{\circ} \mathrm{OH}
\end{aligned}
$$

The superoxide ion in reaction (8) originates from the electron transfer between $\mathrm{TiO}_{2}$ and $\mathrm{O}_{2}$ molecule (reaction (5)).

The electron scavenging by $\mathrm{O}_{3}$ or $\mathrm{O}_{2}$ diminishes the probability for the recombination of the photogenerated electron-hole pair. Additionally, formation of very oxidative radicals (e.g., in reactions (8-10)) also enhances the mineralization efficiency. Besides, UV irradiation of $\mathrm{O}_{3}$ may increase the amount of $\mathrm{H}_{2} \mathrm{O}_{2}$ and $\mathrm{HO}^{\bullet}$ species in the system.

The determining role of hydroxyl radical in the titanium dioxide based photocatalytic degradation of various organic compounds has been confirmed by application of suitable $\mathrm{HO}^{\bullet}$ scavengers. In an independent study, both $t$-butanol and $i$-propanol were applied for this purpose; in both cases the degradation of L-serine was significantly hindered in the presence of these reactants (Szabó-Bárdos 2013). Besides, a similar effect was observed with $p$ benzoquinone, which is an efficient $\mathrm{O}_{2}{ }^{\bullet-}$ scavenger, indicating the considerable role of superoxide too in the mechanism of mineralization of this amino acid.

\subsection{Decay of HBS and formation of sulfate under various conditions}

Beside the change of TOC, i.e., the rate of the mineralization, other quantitative features of the systems such as the actual concentration of HBS and sulfate ions were monitored during the reactions to investigate if synergistic effect can be observed also in the concentration change of these species. The decay rates of HBS (Fig. 1B) are considerably higher than corresponding rates of the TOC change (Fig. 1A). This phenomenon is especially pronounced 
in the case of ozonation, where the initial decay rate is about the same as that observed for the air/ $\mathrm{TiO}_{2} / \mathrm{UV}$ system $\left(0.0040 \mathrm{mM} \mathrm{min}^{-1}\right)$. These results suggest that, in accordance with our earlier observation regarding the photocatalytic mineralization of naphthalene- and benzenesulfonate (Szabó-Bárdos et al. 2008b; Szabó-Bárdos et al. 2011), oxygenation (hydroxylation) is the primary step of the degradation. Notably, incorporation of oxygen into the starting material does not change (decrease) the TOC of the system. This reaction step is relatively efficient also in the ozonation, hence, deviating from the mineralization rates, the decay rate of HBS in the case of the combined procedure $\left(0.0069 \mathrm{mM} \mathrm{min}^{-1}\right)$ does not exceed the sum of the rates observed for the individual methods. This result indicates that the synergic effect originates mostly from the efficient promotion of the degradation of the intermediates formed during the decay of the starting material (HBS).

\section{Insert Fig. 2 about here}

The rate for the formation of sulfate ions in the case of the combined procedure $\left(0.00240 \mathrm{mM} \mathrm{min}^{-1}\right)$ exceeds the sum of the rates observed for the individual methods $\left(0.00090+0.00110 \mathrm{mM} \mathrm{min}^{-1}\right)($ Fig. 2), even if not to that extent as in the case of the TOC changes. This result suggests, in accordance with the previous conclusion, that desulfonation is not a primary step of the mineralization, its rate does not strongly correlate with that of the decay of the starting material. Hence, most of the sulfate ions originated from the intermediates, not directly from the starting material.

The change of $\mathrm{pH}$ during the degradation of HBS displays similar characteristics in all systems examined (Fig. S1). A strong acidification (from $\mathrm{pH}$ ca. 5.7 to about 3 within $60 \mathrm{~min}$ ) could be observed, similarly to the mineralization of other sulfonated surfactants such as naphthalenesulfonates (Szabó-Bárdos et al. 2008b), and benzenesulfonate (Szabó-Bárdos et al. 2011). This phenomenon may be partly attributed to the following reaction: 


$$
\mathrm{RSO}_{3}{ }^{-}+\mathrm{HO}^{\bullet} \rightarrow \mathrm{HSO}_{4}{ }^{-}+\mathrm{R}^{\bullet} \leftrightarrow \mathrm{H}^{+}+\mathrm{SO}_{4}{ }^{2-}+\mathrm{R}^{\bullet}
$$

Thus, the decrease of $\mathrm{pH}$ is partly related to desulfonation. Besides, the formation of organic acids may also contribute to the change of $\mathrm{pH}$ in the first hour of irradiation. Later, at $\mathrm{pH} \leq 3$ their dissociation is negligible, thus the release of sulfuric acid is the determining factor in the decrease of $\mathrm{pH}$.

\subsection{Formation and decay of intermediates under various conditions}

Using the actual concentrations of the starting material (HBS) directly determined by HPLC measurements and the TOC values of the same system (see Fig. 1), the TOC values corresponding to the unreacted HBS could be calculated. The difference between the overall TOC value and that of the unreacted starting material gives the TOC belonging to the intermediates formed (Fig. 3).

Insert Fig. 3 about here

Fig. 3 displays the TOC versus time plots belonging to the intermediates formed during degradation process in all three systems examined. Interestingly, the TOC of the intermediates does not significantly depend on the method applied. This phenomenon may be attributed to that in the case of the individual methods (i.e., $\mathrm{O}_{3} / \mathrm{UV}$ and $\mathrm{air} / \mathrm{TiO}_{2} / \mathrm{UV}$ ) the decay of the mineralization of the intermediates formed is slower than in the combined procedure, where also their formation rate is higher.

Insert Fig. 4 about here

The change of the absorption spectrum of the system during the degradation is in accordance with the formation and decay of intermediates. In the first 50-min period of irradiation the maximum absorbance at about $270 \mathrm{~nm}$ did not significantly changed, while a shoulder arose at $290 \mathrm{~nm}$, indicating the hydroxylation of the starting material (Fig. 4A). At 
longer periods of irradiation a strong decrease of the absorbance at the main bands can be observed (Fig. 4B), due to the cleavage of the aromatic ring, which is the key step of the decay of the hydroxylated intermediates. The formations of the hydroxylated and ring-opened intermediates in this system are supported by HPLC-MS measurements in our earlier work on the degradation of benzenesulfonate (Szabó-Bárdos et al. 2011). The strong correlations between the absorption spectra and the corresponding MS results in that study unambiguously confirm our interpretation.

Similarly to the case of the TOC values, also the sulfur concentrations belonging to the intermediates (in forms of sulfate or sulfonate groups) could be calculated as functions of the irradiation time (Fig. 5). During the calculation, the total (starting) sulfur concentration was reduced by the actual (free) $\left[\mathrm{SO}_{4}{ }^{2-}\right]$ and by the sulfur content of the residual starting material (pollutant).

\section{Insert Fig. 5 about here}

The plots in Fig. 5 indicate that at each point of the degradation process sulfur concentration belonging to the intermediates are highest in the combined procedure. According to these results, the relative sulfur content is highest in the intermediates existing in the system treated by the $\mathrm{O}_{3} / \mathrm{TiO}_{2} / \mathrm{UV}$ technique because the concentration of the intermediates during the irradiation is practically independent of the method applied (see Fig. 3). This phenomenon suggests, in accordance with the ratios of the rates of mineralization (TOC decrease, Fig. 1A) and sulfate formation (Fig. 2), that mineralization of the intermediates (i.e. their transformation into carbon dioxide) in the combined procedure is faster than their desulfonation. HPLC-MS monitoring of the intermediates formed in the photocatalytic degradation of benzenesulfonate confirmed that mineralization of these species could take place to a considerable extent without desulfonation (Szabó-Bárdos et al. 2011). 


\subsection{Mineralization of 2,5-dihydroxybenzenesulfonate (DHBS) under various conditions}

Similarly to 4-hydroxybenzenesulfonate (HBS), the mineralization of 2,5-

dihydroxybenzenesulfonate (DHBS), the other key intermediate of the degradation of benzenesulfonate, was also investigated by application of the individual methods $\left(\mathrm{O}_{3} / \mathrm{UV}\right.$ and air/ $\left.\mathrm{TiO}_{2} / \mathrm{UV}\right)$ as well as their combination $\left(\mathrm{O}_{3} / \mathrm{TiO}_{2} / \mathrm{UV}\right)$.

Insert Fig. 6 about here

Comparing the TOC changes during the degradation of DHBS (Fig. 6) to those in the mineralization of HBS, the rates achieved by the corresponding methods are higher for the dihydroxy than for the hydroxy derivative. These results suggest that an enhanced ,,prehydroxylation" of the parent surfactant (benzenesulfonate) promotes the mineralization process. A higher number of hydroxyl groups on the benzene ring increases the probability of the ring-cleavage under the conditions applied in this study. This effect is most pronounced in the case of ozonation, thus, in the mineralization of DHBS by the combined procedure no or just very slight synergistic effect could be observed.

Deviating from the case of HBS, where the absorption change indicated the formation of intermediates (primarily a dihydroxy derivative as the position of the arising new band suggested) in the first period of irradiation (Fig. 4A), a continuous decrease of the absorbance at the main band (above $290 \mathrm{~nm}$ ) could be observed from the very beginning of the irradiation (Fig. S2). A very slight red shift of the main band indicates the formation of aromatic intermediates (i.e., tri- and tetrahydroxy derivatives) but their decay via ring-cleavage is much faster than their formation, resulting in an overall decrease of the absorbance in this range of wavelength. This observation is in accordance with the enhanced mineralization rates for DHBS compared to those for HBS. The recently published correlations between the spectral 
features and the MS values of the corresponding (multihydroxylated aromatic and ringopened) intermediates (Szabó-Bárdos et al. 2011) also support these results.

\subsection{Degradation of alkylbenzene sulfonates (LAS) in aerated and ozonated systems}

After the examination of the mineralization of HBS and DHBS, two groups of surfactants frequently applied in industrial technologies were studied in the respect of photocatalytic degradation in both aerated and ozonated systems. The first group involved linear alkylbenzene sulfonates with 10-13 carbon atoms in the alkyl chain. Although these widely used detergents are relatively biodegradable, their biomineralization can be accelerated by photocatalytic pre-treatment.

In the first stage of photocatalytic degradation of these anionic surfactants, air-bubbling could not be used for introducing oxygen (and ozone) as electron acceptor in this system because of the strong foaming. Instead, addition of hydrogen peroxide was applied for this purpose. In this case the reaction mixture was circulated by a liquid (peristaltic) pump. In the first stage, during 24-hour irradiation, $110 \mathrm{~cm}^{3} 35 \% \mathrm{H}_{2} \mathrm{O}_{2}$ solution was gradually added to the reaction mixture of $3 \mathrm{dm}^{3}$.

Insert Fig.7 about here

Fig. 7A displays the decay of the surfactants in two runs of irradiation in the first stage. The two plots clearly indicate the high reproducibility of our results. According to them, within the 24-hour period of irradiation the concentration of the starting surfactants decreased below the foaming limit, practically to zero.

After transformation of the starting detergents in the first stage, air-bubbling could be used for introduction of oxygen (and ozone). In this second stage, irradiation was continued for a 21-hour period under aerated or ozonated conditions. Fig. 7B displays the change of the TOC in the system during both the first and the second stages (the dashed line indicates the 
switch between them). Due to the same conditions, in the first stage the plots are very similar, indicating a linear decrease of TOC in the time period of 9-24 h. In the second stage of the mineralization, under aerated conditions the slope of the plot practically did not change compared to that in the first stage, while in the ozonated system the mineralization rate dramatically increased. These results clearly demonstrate that combination of heterogeneous photocatalysis with ozonation considerably enhances (i.e., multiplies) the efficiency of the mineralization of these surfactants.

\subsection{Degradation of alkyl ether sulfates (LES) in aerated and ozonated systems}

The second group of industrial surfactants examined involved linear alkyl ether sulfates with 10-13 carbon atoms in the alkyl chain. The same types of experiments were carried out with them as with the alkylbenzene sulfonates (see the previous section). In order to avoid foaming, also for these surfactants two-stage procedures were applied. In the first stage, without air-bubbling, hydrogen peroxide was used as oxidizer in a closed reactor with circulation by a liquid pump.

Insert Fig. 8 about here

As Fig. 8A shows, the decay of the LES compounds was much faster in the first stage as that of the LAS surfactants; the concentration of the previous detergents decreased from $520 \mathrm{mg}$ $\mathrm{dm}^{-3}$ to $34 \mathrm{mg} \mathrm{dm}^{-3}$ (below the foaming limit) within 3 hours, although only $20 \mathrm{~cm}^{3} 35 \%$ $\mathrm{H}_{2} \mathrm{O}_{2}$ solution was added to the reaction mixture. The initial rate of the decay of LES was 224 $\mathrm{mg} \mathrm{dm}{ }^{-3} \mathrm{~h}^{-1}$ compared to that of the LAS (56 mg dm $\mathrm{m}^{-3} \mathrm{~h}^{-1}$, see Fig. 7A). This fourfold increase of the decay rate can be attributed to the structural difference between the two types of surfactants. In the case of LES the oxygen-containing ether parts promote the oxidative fractionation of these detergents, while in the LAS compounds no oxygen atoms are involved in the organic parts of the molecules. 
Also the rate of the TOC change, both in the first and in the second stage (Fig. 8B) was significantly higher for the LES compounds than for the LAS detergent. This considerable difference $\left(14.5 \mathrm{mg} \mathrm{dm}^{-3} \mathrm{~h}^{-1}\right.$ vs. $9.6 \mathrm{mg} \mathrm{dm}^{-3} \mathrm{~h}^{-1}$ initial rates in the ozonated systems) can be accounted for the above mentioned structural feature. Moreover, the aromatic ring in the LAS surfactants further hinders their mineralization, due to its extra stability. Hence, 45-hour irradiation was needed for about $85 \%$ mineralization of the LAS compounds, while almost total mineralization of the LES compounds was achieved in about 30 hours by the combined procedure $\left(\mathrm{O}_{3} / \mathrm{TiO}_{2} / \mathrm{UV}\right)$. The difference between the efficiencies in the aerated systems is even more pronounced.

The possibility of the reutilization of the $\mathrm{TiO}_{2}$ catalyst was also tested. After separation by sedimentation and filtration, the used titanium dioxide was rinsed by distilled water, and subsequently applied again under the same conditions as before. In accordance with our earlier observation in a similar system (Szabó-Bárdos et al. 2008a), the activity of the catalyst did not change, i.e., the degradation rate of the pollutants studied did not decreased at all compared to the usage of fresh $\mathrm{TiO}_{2}$. This result also supports the practical applicability of the method investigated.

\section{Conclusions}

Our results clearly demonstrate that the combination of titanium dioxide based heterogeneous photocatalysis with ozonation results in a synergistic effect in the oxidative degradation of hydroxy and dihydroxybenzenesulfonates, achieving a significantly higher mineralization efficiency than the sum of those of the individually applied methods. Manifestation of the advantage of this combined procedure could also be realized by the treatment of widely used industrial surfactants, linear alkylbenzene sulfonates and alkyl ether sulfates. Hence, this combination may be applied for the removal of these pollutants from real wastewaters, either 
as a preparatory procedure before the biological treatment or as a final stage, depending on the requirements of purity and costs, and on the type and concentration of the contaminants to be removed

\section{Acknowledgment}

This work was supported by the Hungarian Scientific Research Fund (OTKA No. K101141 and K81843) and the Hungarian Government and the European Union, with the co-funding of the European Social Fund (TÁMOP-4.2.2.A-11/1/KONV-2012-0071 and TÁMOP-4.2.4.A/211/1-2012-0001).

\section{Literature Cited}

Abu-Hassan MA, Kim JK, Metcalfe IS, Mantzavinos D (2006) Kinetics of low frequency sonodegradation of linear alkylbenzene sulfonate solutions. Chemosphere 62:749-755

Agustina TE, Ang HM, Vareek VK (2005) A review of synergistic effect of photocatalysis and ozonation on wastewater treatment. J Photochem Photobiol C:Rev 6:264-273

Amano R, Tomizawa S, Tezuka M (2004) Mineralization of aqueous benzenesulfonates by contact glow discharge electrolysis. Electrochem 72:836-838

Amano R, Tezuka M (2006) Mineralization of alkylbenzenesulfonates in water by means of contact glow discharge electrolysis. Water Res 40:1857-1863

Arslan-Alaton I, Yalabik AB, Olmez-Hanci T (2010) Development of experimental design models to predict Photo-Fenton oxidation of a commercially important naphthalene sulfonate and its organic carbon content. Chem Eng J 165:597-606

Avetta P, Bianco Prevot A, Fabbri D, Montoneri E, Tomasso L (2012) Photodegradation of naphthalene sulfonic compounds in the presence of a bio-waste derived sensitizer. Chem Eng J 197:193-198

Brilon C, Beckmann W, Knackmuss HJ (1981) Catabolism of naphthalenesulfonic acids by Pseudomonas sp. A3 and Pseudomonas sp. C22. Appl Environ Microbiol 42:44-55

Cain RB (1981) In: Leisinger T, Cook AM, Hutter R, Nuesch J (Eds.) Microbial metabolism of xenobiotics and recalcitrant compounds. Academic Press, London, pp 325-370 
Fabbri D, Bianco Prevot A, Pramauro E (2006) Effect of surfactant microstructures on photocatalytic degradation of phenol and chlorophenols. Appl Catal B:Environ 62:21-27

Faria PCC, Órfão JJM, Pereira MFR (2008) Catalytic ozonation of sulfonated aromatic compounds in the presence of activated carbon. Appl Catal B:Environ 83:150-159

Fernández J, Riu J, García-Calvo E, Rodríguez A, Fernández-Alba AR, Barceló D (2004) Determination of photodegradation and ozonation by products of linear alkylbenzene sulfonates by liquid chromatography and ion chromatography under controlled laboratory experiments. Talanta 64:69-79

Greim H, Ahlers J, Bias R, Broecker B, Hollander H, Gelbke HP, Klimisch HJ, Mangelsdorf I, Paetz A, Schong N, Stropp G, Vogel R, Weber C, Ziegler-Skylakakis K, Bayer E (1994) Toxicity and ecotoxicity of sulfonic acids: structure activity relationship. Chemosphere 28:2203-2236

Hashim MA, Kulandai J, Hassan RS (1992) Biodegradability of branched alkybenzene sulfonates. J Chem Tech Biotech 54:207-214

Hoffmann MR, Martin ST, Choi W, Bahnemann DW (1995) Environmental applications of semiconductor photocatalysis. Chem Rev 95:69-96

Horváth O, Huszánk R (2003) Degradation of Surfactants by Hydroxyl Radicals Photogenerated from Hydroxoiron(III) Complexes. Photochem Photobiol Sci 2:960-966

Horváth O, Bodnár E, Hegyi J (2005) Photoassisted oxidative degradation of surfactants and simultaneous reduction of metals in titanium dioxide dispersions. Colloid Surf A: Physicochem Eng Aspects 265:135-140

Isobe KO, Zakaria MP, Chiem NH, Minh LY, Prudente M, Boonyatumanond R, Saha M, Sarkar S, Takada H (2004) Distribution of linear alkylbenzenes (LABs) in riverine and coastal environments in South and Southeast Asia. Water Res 38:2449-2459

Kirk AD, Namasivayam C (1983) Errors in ferrioxalate actinometry. Anal Chem 55:2428-2429

Li L, Zhu W, Chen L, Zhang P, Chen Z (2005) Photocatalytic ozonation of dibutyl phthalate over $\mathrm{TiO}_{2}$ film. J Photochem Photobio A:Chem 175:172-177

Oyama T, Yanagisawa I, Takeuchi M, Koike T, Serpone N, Hidaka H (2009) Remediation of simulated aquatic sites contaminated with recalcitrant substrates by $\mathrm{TiO}_{2} /$ ozonation under natural sunlight. Appl Catal B:Environ 91:242-246

Patsoura A, Kondarides DI, Verykios EX (2007) Photocatalytic Degradation of Organic Pollutants with Simultaneous Production of Hydrogen. Catal Today 124:94-102 
Rabek JF (1982) Experimental methods in photochemistry and photophysics. WileyInterscience publication, John Wiley \& Sons Ltd., New York, pp 944-946

Ravera M, Ciccarelli C, Gianotti V, Scorz, S, Osella D (2004) Electro-assisted methods for waste destruction: silver(II) and peroxydisulfate reagents in the electrochemically mediated oxidation of polyaromatic sulfonates. Chemosphere 57: 587-594

Ravera M, Buico A, Gosetti F, Cassino C, Musso D, Osella D (2009) Oxidative degradation of 1,5-naphthalenedisulfonic acid in aqueous solutions by microwave irradiation in the presence of $\mathrm{H}_{2} \mathrm{O}_{2}$. Chemosphere 74:1309-1314

Ravera M, Musso D, Gosetti F, Cassino C, Gamalero E, Osella D (2010) Oxidative degradation of 1,5-naphthalenedisulfonic acid in aqueous solutions: non-catalytic remediation by UV-photolysis in the absence and presence of $\mathrm{H}_{2} \mathrm{O}_{2}$. Chemosphere 79:144-148

Reemtsma T (1996) Methods of analysis of polar aromatic sulfonates from aquatic environments. J Chromatog A 733:473-489

Salvador P (2007) On the nature of photogenerated radical species active in the oxidative degradation of dissolved pollutants with $\mathrm{TiO}_{2}$ aqueous suspensions: A revision in the light of the electronic structure of adsorbed water. J Phys Chem C 111:17038-17043

Sangchakr B, Hisanaga T, Tanaka K (1995) Photocatalytic degradation of sulfonated aromatics in aqueous $\mathrm{TiO}_{2}$ suspension. J Photochem Photobiol A:Chem 85:187-190

Szabó-Bárdos E, Czili H, Horváth A (2003) Photocatalytic oxidation of oxalic acid enhanced by silver deposition on $\mathrm{TiO}_{2}$ surface. J Photochem Photobiol A:Chem 154:195-201

Szabó-Bárdos E, Czili H, Megyery-Balog K, Horváth A (2004) Photocatalytic oxidation of oxalic acid enhanced by silver and copper deposition on $\mathrm{TiO}_{2}$ surface. Progr Colloid Polym Sci 125:42-48

Szabó-Bárdos E, Zsilák Z, Horváth O (2008a) Photocatalytic degradation of anionic surfactant in titanium dioxide suspension. Progr Colloid Polym Sci 135:21-28

Szabó-Bárdos E, Zsilák Z, Lendvay G, Horváth O, Markovics O, Hoffer A, Törő N (2008b) Photocatalytic degradation of 1,5-naphthalenedisulfonate on colloidal titanium dioxide. J Phys Chem B 112:14500-14508

Szabó-Bárdos E, Markovics O, Horváth O, Törő N, Kiss G (2011) Photocatalytic degradation of benzenesulfonate on colloidal titanium dioxide. Water Res 45:1617 - 1628 .

Szabó-Bárdos E (2013) PhD Dissertation, University of Pannonia, Veszprém.

Tjahjanto RT, Galuh R. D, Wardani S (2012) Ozone determination: A comparison of quantitative analysis methods. J Pure App Chem Res 1:18-25 
Takada H, Ishiwatari R (1990) Biodegradation experiments of linear alkylbenzenes (LABs): isomeric composition LABs as an indicator of the degree of LAB degradation in the aquatic environment. Environ Sci Tech 24:86-91

Tully PS (1997) In: Grant MH, editor. Kirk-Othmer encyclopedia of chemical technology. 4th ed., vol. 23. New York, JohnWiley \& Sons, p 194

Wittich R, Rast HG, Knackmuss HJ (1988) Degradation of naphthalene-2,6- and naphthalene1,6-disulfonic acid by a Moraxella sp. Appl Environ Microbiol 54:1842-1844

Zhang T, Oyama T, Horikoshi S, Zhao J, Serpone N, Hidaka H (2003) Photocatalytic decomposition of the sodium dodecylbenzene sulfonate surfactant in aqueous titania suspensions exposed to highly concentrated solar radiation and effects of additives. Appl Catal B:Environ 42:13-24

Zsilák Z, Szabó-Bárdos E, Fónagy O, Horváth O, Horváth K, Hajós P (2013) Degradation of benzenesulfonate by heterogeneous photocatalysis combined with ozonation. Catal Today (in press), http://dx.doi.org/10.1016/j.cattod.2013.10.039

Zürrer D, Cook AM, Leisinger Th (1987) Microbial desulfonation of substituted naphthalenesulfonic acids and benzenesulfonic acids. Appl Environ Microbiol 53:1459-1463 


\section{Figure captions}

Fig. 1 Change of the total organic carbon (TOC) content (A) and the concentration of the starting material (HBS) (B) as functions of time in the system containing $1 \times 10^{-3} \mathrm{M} \mathrm{HBS}$ during the treatment by various oxidation methods: $(\boldsymbol{\Delta}) \mathrm{O}_{3}+\mathrm{UV},(\mathrm{O})$ air+ $\mathrm{TiO}_{2}+\mathrm{UV},(\bullet)$ $\mathrm{O}_{3}+\mathrm{TiO}_{2}+\mathrm{UV}$. $\left(\mathrm{TiO}_{2}\right.$ content is $\left.1 \mathrm{~g} \mathrm{dm}^{-3}\right)$

Fig. 2 Change of the sulfate concentration as functions of time in the system containing $1 \times 10^{3}$ M HBS during the treatment by various oxidation methods: $(\boldsymbol{\Delta}) \mathrm{O}_{3}+\mathrm{UV},(\mathrm{O})$ air+TiO $\mathrm{TiO}_{2}+$ $\mathrm{UV},(\bullet) \mathrm{O}_{3}+\mathrm{TiO}_{2}+\mathrm{UV}$. $\left(\mathrm{TiO}_{2}\right.$ content is $\left.1 \mathrm{~g} \mathrm{dm}^{-3}\right)$

Fig. 3 Change of TOC belonging to the intermediates during the mineralization in the system containing $1 \times 10^{-3} \mathrm{M}$ HBS and treated by various oxidation methods: $(\boldsymbol{\Delta}) \mathrm{O}_{3}+\mathrm{UV}$, (O) $\mathrm{air}+\mathrm{TiO}_{2}+\mathrm{UV},(\bullet) \mathrm{O}_{3}+\mathrm{TiO}_{2}+\mathrm{UV}$. $\left(\mathrm{TiO}_{2}\right.$ content is $\left.1 \mathrm{~g} \mathrm{dm}^{-3}\right)$

Fig. 4 Change of the absorption spectrum of the bulk solution during the combined $\left(\mathrm{O}_{3}+\mathrm{TiO}_{2}\right.$ $+\mathrm{UV})$ treatment of the system containing $1 \times 10^{-3} \mathrm{M} \mathrm{HBS}$ and $1 \mathrm{~g} \mathrm{dm}^{-3} \mathrm{TiO}_{2} .(\ell=1.0 \mathrm{~cm})$. The samples were taken at the indicated times in $\min$

Fig. 5 Change of the sulfur content belonging to the intermediates during the mineralization in the system containing $1 \times 10^{-3} \mathrm{M}$ HBS and treated by various oxidation methods: $(\mathbf{A}) \mathrm{O}_{3}+$ $\mathrm{UV},(\mathrm{O})$ air $+\mathrm{TiO}_{2}+\mathrm{UV},(\bullet) \mathrm{O}_{3}+\mathrm{TiO}_{2}+\mathrm{UV}$. $\left(\mathrm{TiO}_{2}\right.$ content is $\left.1 \mathrm{~g} \mathrm{dm}^{-3}\right)$

Fig. 6 Change of the total organic carbon (TOC) content as functions of time in the system containing $1 \times 10^{-3} \mathrm{M}$ DHBS during the treatment by various oxidation methods: $(\boldsymbol{\Delta}) \mathrm{O}_{3}+$ $\mathrm{UV},(\mathrm{O})$ air $+\mathrm{TiO}_{2}+\mathrm{UV},(\bullet) \mathrm{O}_{3}+\mathrm{TiO}_{2}+\mathrm{UV}$. $\left(\mathrm{TiO}_{2}\right.$ content is $\left.1 \mathrm{~g} \mathrm{dm}^{-3}\right)$

Fig. 7 Change of the concentration of the starting material (LAS) during the photocatalytic treatment in the first stage $\left(\mathrm{H}_{2} \mathrm{O}_{2}+\mathrm{TiO}_{2}+\mathrm{UV}\right)(\mathrm{A})$; and the total organic carbon (TOC) content in the first $\left(\mathrm{H}_{2} \mathrm{O}_{2}+\mathrm{TiO}_{2}+\mathrm{UV}\right)$ and the second stage as well (the dashed line indicates the switch between the two stages) (B) as functions of time in the system containing $1 \mathrm{~g} \mathrm{dm}^{-3}$ LAS sample and $1 \mathrm{~g} \mathrm{dm}^{-3} \mathrm{TiO}_{2}$. In part A the different markers designate the data points belonging to two independent run of experiments. In the second stage (in part B) two oxidation methods were applied: $(\mathrm{O})$ air $+\mathrm{TiO}_{2}+\mathrm{UV},(\bullet) \mathrm{O}_{3}+\mathrm{TiO}_{2}+\mathrm{UV}$

Fig. 8 Change of the concentration of the starting material (LES) during the photocatalytic treatment in the first stage $\left(\mathrm{H}_{2} \mathrm{O}_{2}+\mathrm{TiO}_{2}+\mathrm{UV}\right)(\mathrm{A})$; and the total organic carbon (TOC) content in the first $\left(\mathrm{H}_{2} \mathrm{O}_{2}+\mathrm{TiO}_{2}+\mathrm{UV}\right)$ and the second stage as well (the dashed line indicates the switch between the two stages) (B) as functions of time in the system containing $1 \mathrm{~g} \mathrm{dm}^{-3}$ LAS sample and $1 \mathrm{~g} \mathrm{dm}^{-3} \mathrm{TiO}_{2}$. In the second stage (in part $\mathrm{B}$ ) two oxidation methods were applied: (O) air+TiO $+\mathrm{UV},(\bullet) \mathrm{O}_{3}+\mathrm{TiO}_{2}+\mathrm{UV}$ 
Fig1
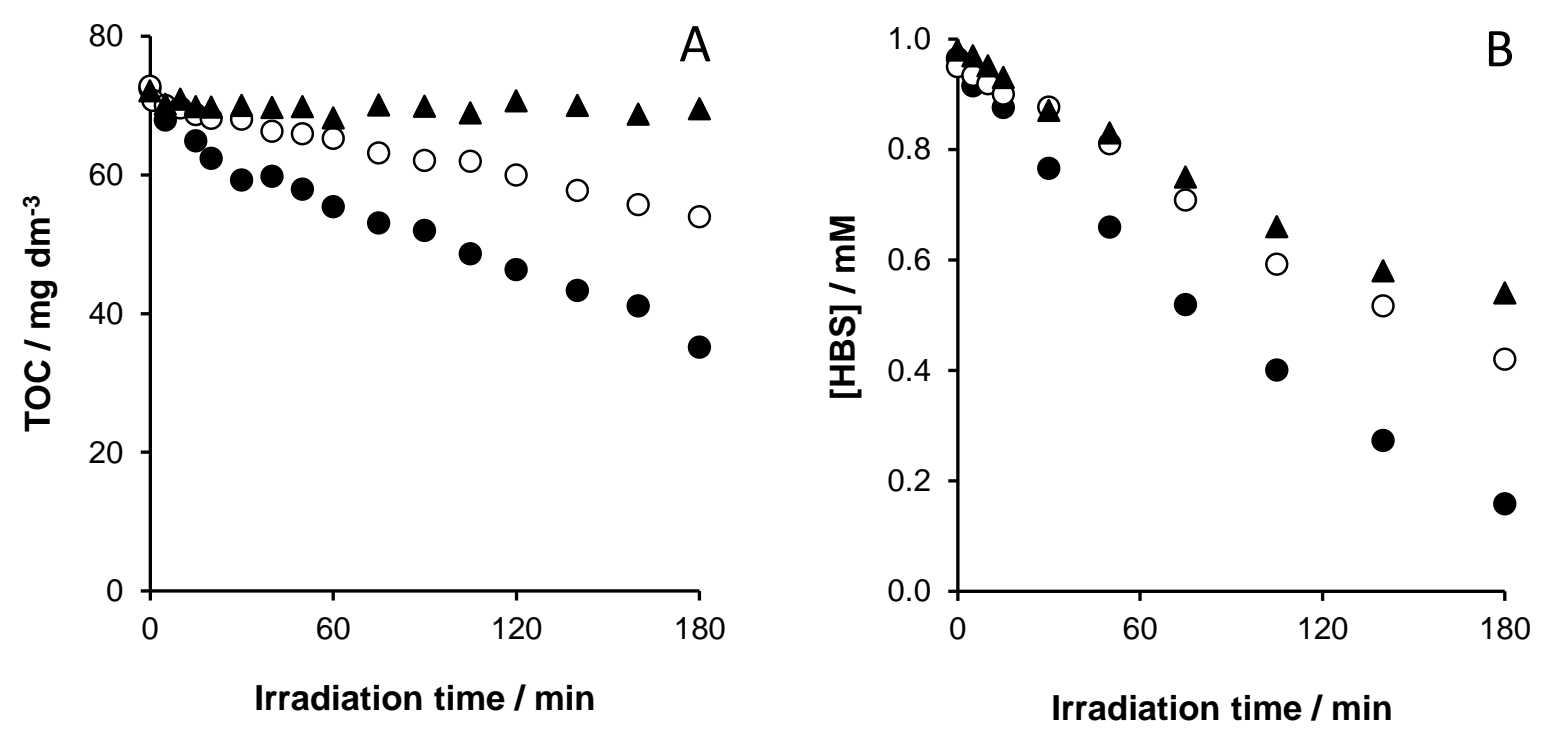

Fig2

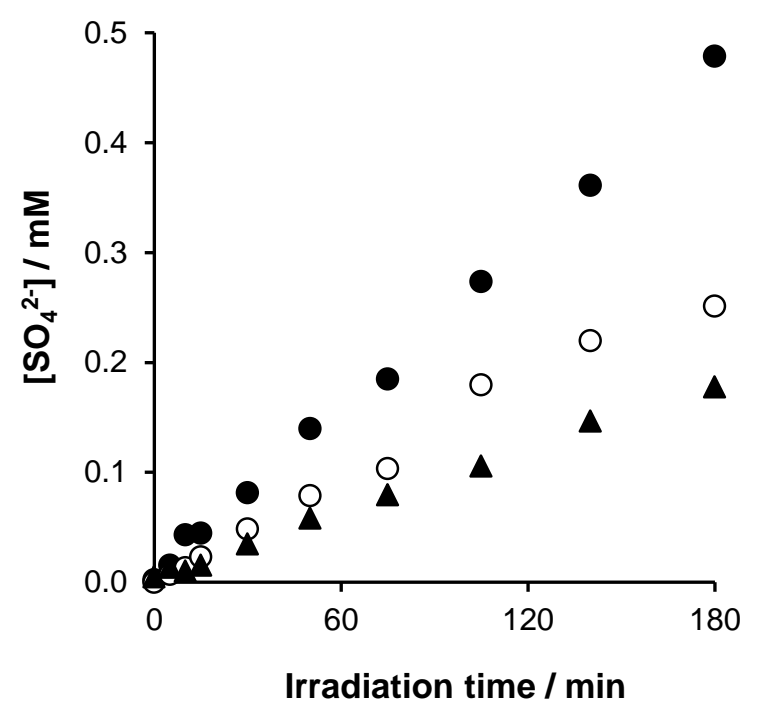


Fig3

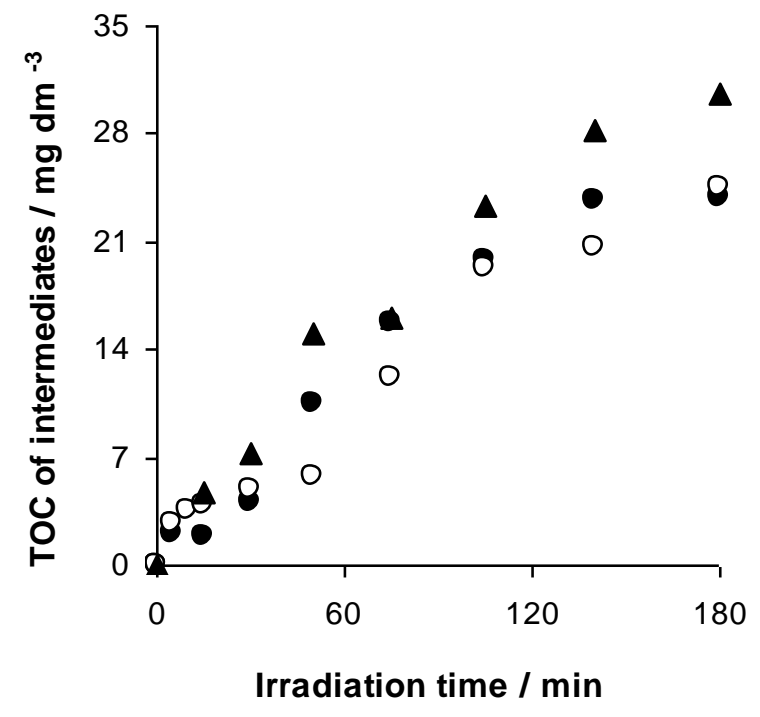

Fig4
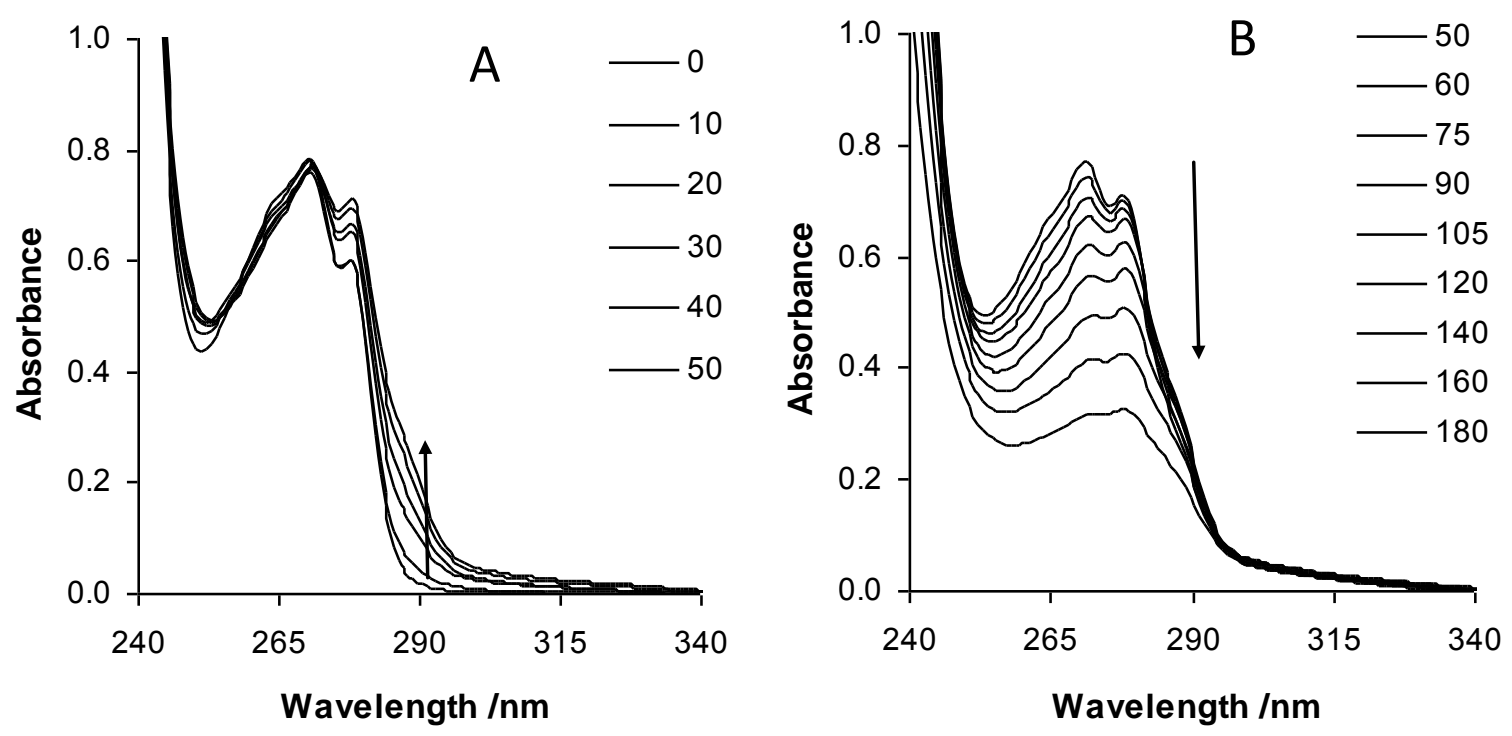
Fig5

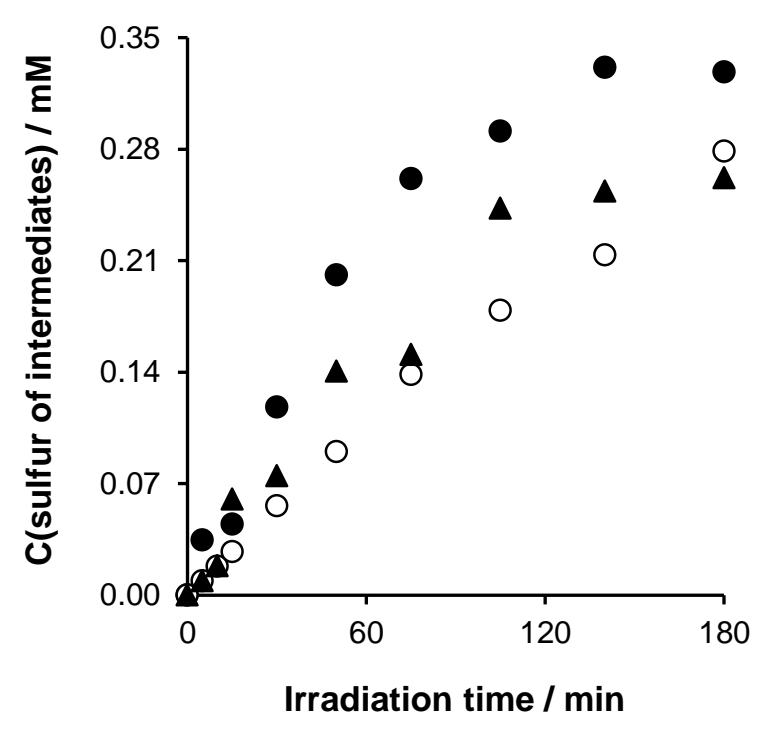

Fig6

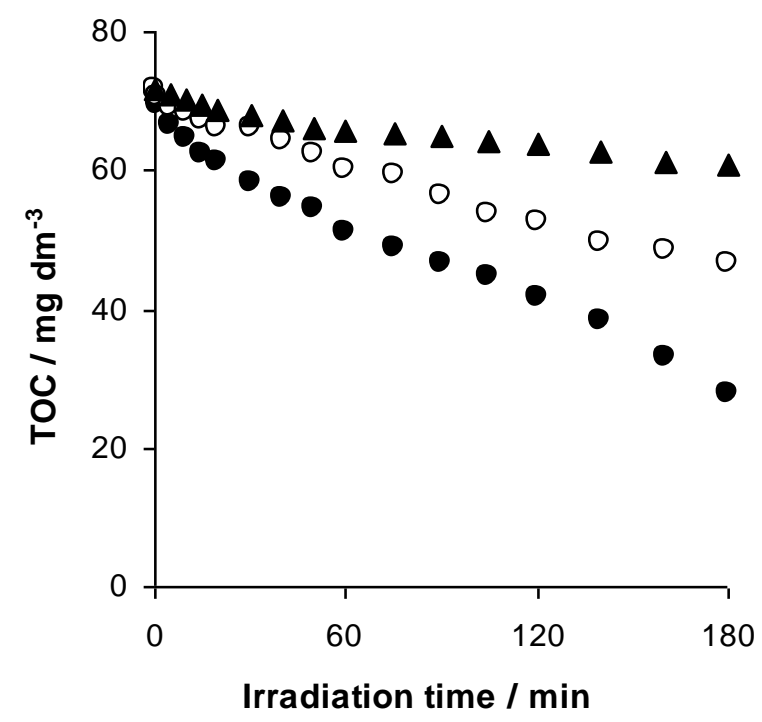



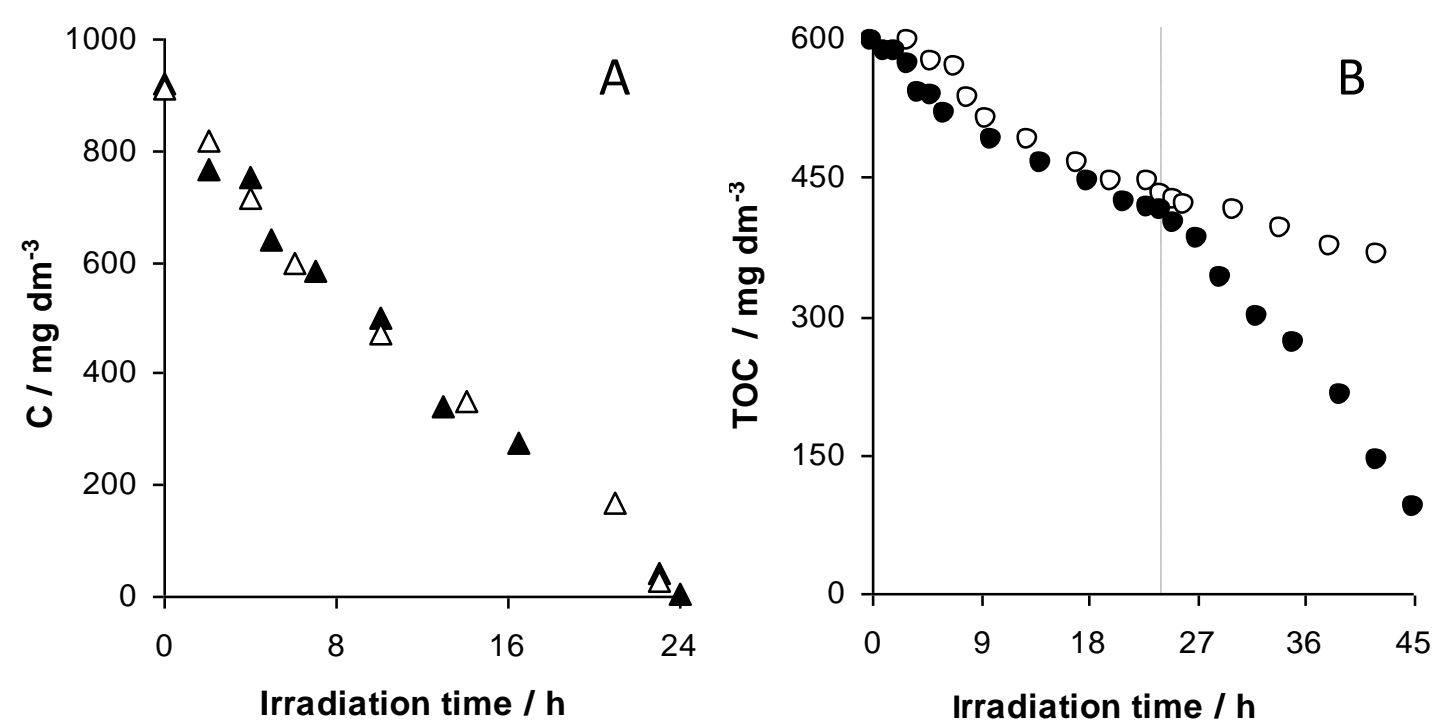

Fig8
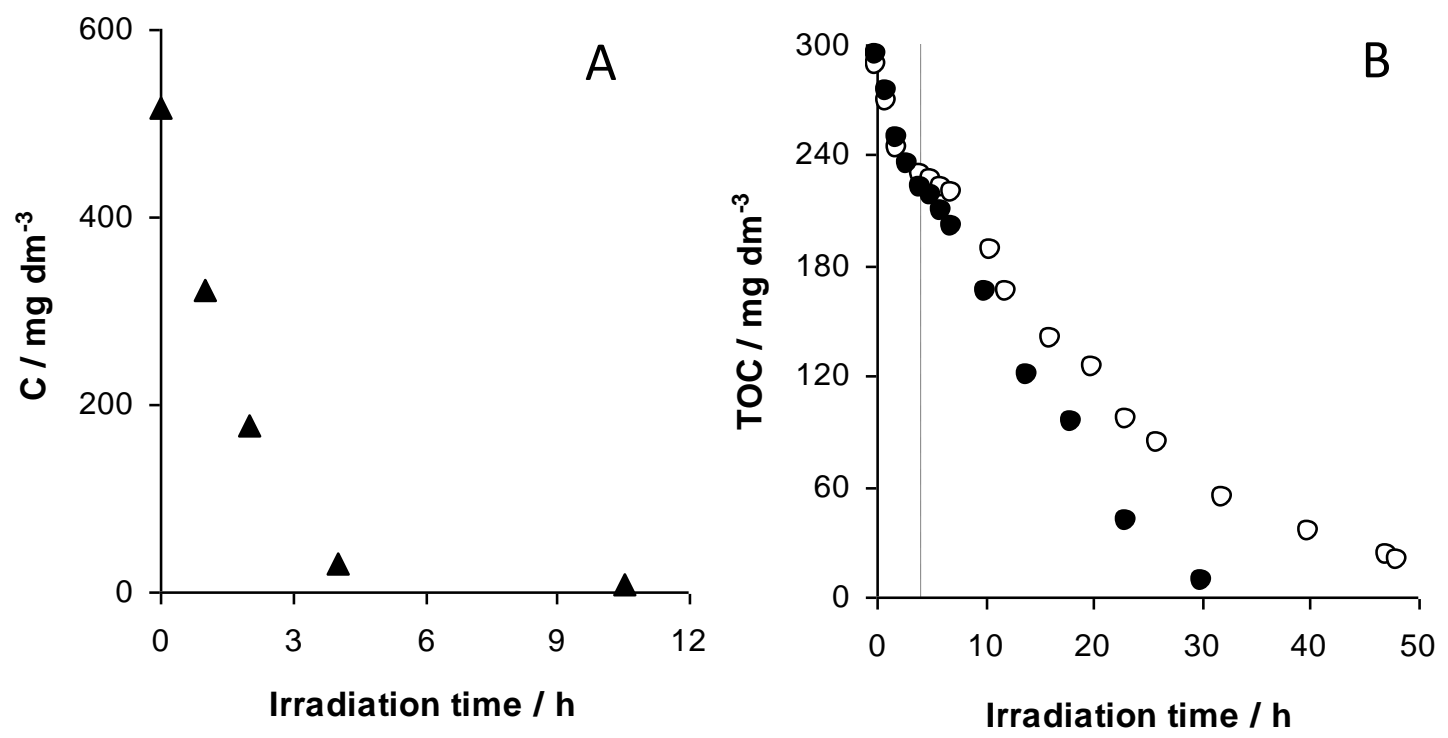